\title{
Two types of states: A cross-linguistic study of change-of-state verb roots
}

\author{
John Beavers, Michael Everdell, Kyle Jerro, Henri Kauhanen, Andrew Koontz-Garboden, Elise \\ LeBovidge, and Stephen Nichols*
}

\begin{abstract}
Event structural theories decompose verb meanings into an event template and idiosyncratic root. Many mainstream theories assume a bifurcation in the kinds of entailments contributed by roots and templates, in particular that lexical entailments of change of an individual in change-of-state verbs are only introduced by templates, not roots. We argue against such theories by comparing Levin's (1993) non-deadjectival vs. deadjectival change-of-state verb roots (e.g. crack vs. red roots). A broad-scale typological study reveals that red-type roots tend to have simple (e.g. non-deverbal) stative forms, but crack-type roots do not. Semantic studies of Kakataibo and English show that terms built on crack-type roots always entail change, while terms based on red-type roots may not. We thus suggest that crack-type roots entail change-of-state, contra Bifurcation.
\end{abstract}

Keywords. Lexical semantics, events, event structure, change-of-state, root, typology

1. Introduction. In much work in lexical semantics verb meanings are assumed to consist at least partly of an "event structure" constraining the events described by the verb, consisting of (a) an event template built from basic event-denoting predicates like CAUSE and BECOME that define the broad temporal and causal contours of the event and (b) some idiosyncratic "root" filling in real world meanings such as specific states or actions for a given verb's template (see e.g. Dowty 1979, Rappaport Hovav \& Levin 1998). In one modern implementation a verb's event structure corresponds to a phrase structural object built from functional heads (e.g. v; Marantz 1997, Ramchand 2008, Harley 2012) that define the template and an (acategorial) morphological root that defines the lexical semantic root information. For example, caused change-of-state verbs like flatten or crack can be viewed as surface realizations of underlying event structures consisting of state-denoting roots that combine with functional heads introducing CAUSE and BECOME meanings (e.g. Hale \& Keyser 2002, Embick 2004).

(1) a. John flattened the $\operatorname{rug} \approx\left[{ }_{v \mathrm{P}} \operatorname{John}\left[v^{\prime} v_{\text {cause }}\left[v \mathrm{P}\right.\right.\right.$ the rug $\left.\left.\left.\left[-e n_{v_{\text {become }}} \sqrt{f l a t}\right]\right]\right]\right]$

b. Kim cracked a vase $\approx\left[{ }_{v \mathrm{P}} \operatorname{Kim}\left[v^{\prime} v_{\text {cause }}\left[v \mathrm{P}\right.\right.\right.$ a vase $\left.\left.\left.\left[v^{\prime} v_{\text {become }} \sqrt{\text { cracked }}\right]\right]\right]\right]$

In most event structural approaches, the template defines the verb's lexical aspectual properties (e.g. its aspectual class), argument structure (e.g. the number arguments it takes and how they are realized), and regular derivational morphology (e.g. -en morphology in (1a)), while the root mainly just determines the verb's idiosyncratic meaning and morphology (e.g. flat vs. crack).

\footnotetext{
*This material is based upon work supported by the National Science Foundation under grant no. BCS-1451765. All data we collected for this study will soon be available online at https://verbal-roots.la.utexas . edu/. We thank Luke Adamson, Heidi Harley, Larry Horn, Beth Levin, and Daniel Valle for their feedback. Au-thors: John Beavers, The University of Texas at Austin (jtbeavers@utexas.edu), Michael Everdell, The University of Texas at Austin (everdellm@utexas.edu), Kyle Jerro, The University of Texas at Austin (jerrokyle@utexas.edu), Henri Kauhanen, The University of Manchester (henri.kauhanen@manchester.ac.uk), Andrew Koontz-Garboden, The University of Manchester (andrewkg@manchester.ac.uk), Elise LeBovidge, The University of Texas at Austin (eliseanne@utexas.edu), and Stephen Nichols, The University of Manchester (stephen.nichols@ manchester.ac.uk).
} 
While much work has focused on the meanings of basic notions like CAUSE and BECOME, one under-explored question (though see Dowty 1979, Goldberg 1995, Wechsler 2005 , inter alia, for related discussion) is what the contribution of the root is and in particular whether there is a clean divide between meanings entailed by roots and by templatic heads. For example, are entailments tied to CAUSE and BECOME introduced solely by the template, so that any time a verb gives rise to such an entailment there must be a corresponding $v$ of the appropriate sort, with its concomitant grammatical reflexes? Or can a root introduce these entailments independently of the template it occurs in? A common implicit and sometimes explicit assumption in many event structural works is that entailments introduced by templates are excluded from roots, for example as outlined in Embick's (2009) "Bifurcation Thesis for Roots" (BTR) and Arad's (2005) "Root Hypothesis" (see also Borer 2005, Dunbar \& Wellwood 2016). Such a clean divide makes two predictions: (a) all change-of-state verbs should have identical templatic structures (e.g. they must include an appropriate $v$ to introduce an entailment of change) and (b) when the roots of change-of-state verbs are used in templates lacking entailments of change no such reading should arise.

Based primarily on data from English, Koontz-Garboden \& Beavers (2017) argue against the BTR for change-of-state verbs, proposing that roots of some change-of-state verbs entail change (see also Beavers \& Koontz-Garboden 2017 on possession in the roots of ditransitive verbs). In this paper, we present a broad typological and cross-linguistic study into this question as pertains to change entailments in the roots of change-of-state verbs - entailments that are uncontroversially assumed to be templatic on all event structural approaches we are aware of. We show that across languages certain root classes entail change regardless of the template and show morphosyntactic properties indicating that they are derived in distinct ways not predicted by the BTR. Thus some roots entail templatic meaning, which furthermore has grammatical effects and ultimately argues against the BTR (see also Beavers \& Koontz-Garboden in prep).

2. Change-of-state roots. One major consequence of the BTR is that it entails that the roots of change-of-state verbs should be purely stative in the sense that they themselves should not carry lexical entailments of change-of-state. It follows from this that change-of-state verbs must contain a $v_{\text {become }}$ head on an analysis like the one in (1a) for that meaning to arise. We argue first and foremost that while this may be correct for some change-of-state verbs, it is certainly not for others (see also Megerdoomian 2002, Koontz-Garboden 2006). In particular, we distinguish two types of roots that may form the basis of change of state verbs, building on a distinction outlined in Dixon (1982: 50): Dixon's property concept (PC) roots, which form the basis of verbs and adjectives having to do with concepts related to dimension, age, color, value, etc. (essentially the roots of Levin's 1993: 245 deadjectival change-of-state verbs), vs. what we call result roots, which form the basis of change-of-state verbs and adjectives having to do with physical damage, cooking, killing etc. (essentially Levin's various non-deadjectival change-of-state verbs):

(2) PC root change-of-state verbs (deadjectival change-of-state verbs): awaken, brighten, broaden, cheapen, coarsen, dampen, darken, deepen, fatten, flatten, freshen, gladden, harden, hasten, heighten, lengthen, lessen, lighten, loosen, moisten, neaten, quicken, ripen, roughen, sharpen, shorten, sicken, slacken, smarten, soften, stiffen, straighten, strengthen, sweeten, tauten, thicken, tighten, toughen, weaken, widen, ...

(3) Result root change-of-state verbs (non-deadjectival change-of-state-verbs): 
a. Levin's (1993:241) break verbs: break, chip, crack, crash, crush, fracture, rip, shatter, ...

b. Levin's cooking verbs (Levin 1993: 243): bake, barbecue, blanch, boil, braise, broil, charbroil, charcoal-broil, coddle, cook, crisp, deepfry, fry, grill, ...

c. Verbs of killing (Levin 1993: 230ff.; Beavers \& Koontz-Garboden 2012): crucify, electrocute, drown, hang, guillotine, ...

There are morphological and semantic arguments that while PC change-of-state verbs are built on state-denoting roots lacking templatic entailments, result root verbs are not, contra the BTR and related assumptions in the literature. In $\S 3$ and $\S 4$ we show that in English result roots but not PC roots entail change, recapping Koontz-Garboden \& Beavers (2017). In $\S \S 5-6$ we explore these from a cross-linguistic perspective and show that the same patterns hold in other languages. We conclude with a sketch of a formal analysis in $\S 7$.

3. Morphological observations. In terms of morphology, the BTR makes several key predictions, including the prediction that, barring lexical idiosyncrasy, all roots of change-of-state verbs should show all of the same stative, inchoative, and causative forms. We focus here on stative forms (see also Koontz-Garboden 2005, 2007, 2009a for observations about inchoative and causative forms). In English, PC roots generally show two stative forms, one a simple, underived adjective as in (4a) and one adjective derived from a verb that itself shows verbalizing -en morphology deriving it from the simple adjective:

(4) a. Look at the bright picture on your left.

b. Look at the brightened picture on your left.

There is of course also a semantic difference: the simple adjective bright describes something that may have always been bright (i.e. a simple state), while the derived adjective brighten describes something that has undergone a brightening process (i.e. a result state). Embick (2004) analyzes these as the same root occurring in two adjectivalizing contexts: one consisting of just a root with the adjectivalizing head Asp as in (5a), and one consisting of a root plus a verbalizing $v_{\text {become }}$ head that are adjectivalized by a head $\mathrm{Asp}_{R}$ as in (5b):
a. Basic states (cp. Embick 2004: 363): [AspP Asp $\sqrt{\text { Root }] ~}$
b. Result states (cp. Embick 2004: 367): [AspP $\operatorname{Asp}_{R}\left[{ }_{v \mathrm{P}} \mathrm{DP} v_{\text {become }} \sqrt{\text { Root }}\right]$

The presence of $v_{\text {become }}$ in $(5 \mathrm{~b})$ ensures that change is part of the meaning of the adjective.

Crucially, however, with change-of-state verbs built from result roots, there is only one adjectival form, the deverbal -ed/en form corresponding to (4b).

(6) broken, chipped, cracked, crashed, crushed, fractured, ripped, shattered, smashed, snapped, splintered, split, torn, baked, barbecued, blanched, boiled, braised, ...

There are no distinct simple adjectives corresponding to (4a). Yet under the BTR, any stative root should be able to appear in either structure in (5) and thus derive two distinct types of adjectives. Embick (2004: 358) claims, however, that the roots of (6) do in fact appear in both of (5), but what makes result roots different from $\mathrm{PC}$ roots is that with result roots both Asp and $\mathrm{Asp}_{R}$ are overtly realized as -ed/en while with PC roots only $\mathrm{Asp}_{R}$ is realized as -ed/en while Asp is null. In other words, (6) are all technically structurally ambiguous between the two types of adjectives, but this is obscured by homophony. This is considered an accident of English — it just happens that there 
are two classes of roots regarding surface morphology. However, if it is an accident it should not recur across languages, or if it does, there is no expectation that the same root meanings will show the same asymmetries. We argue below that the morphological contrast between stative uses of $\mathrm{PC}$ and result roots in English is not an accident, but recurs in other languages.

4. The lexical semantics of the two kinds of roots. The BTR also gives rise to semantic predictions about the derivatives of roots of change of state verbs:

(7) a. Simple adjectives based on PC roots (e.g. red) will not entail prior change.

b. Derived adjectives based on PC roots (e.g. reddened) will entail prior change.

c. Adjectives based on result roots (e.g. broken) should not entail prior change since they are ambiguous between (5a) and (5b) and could always in context be realizing (5a).

Predictions $(7 \mathrm{a}, \mathrm{b})$ are borne out, shown by acceptability in contexts where change is denied:

(8) a. The red dirt has never (been) reddened.

b. The long river has never (been) lengthened.

c. The short rod has never (been) shortened.

d. The bright photo has never (been) brightened.

(9) a. \#The reddened dirt has never (been) reddened.

b. \#The lengthened river has never (been) lengthened.

c. \#The shortened rod has never (been) shortened.

d. \#The brightened photo has never (been) brightened.

Simple adjectives may appear in a context with a negated change-of-state, i.e. they do not entail prior change (7a). Conversely, the derived adjectives are unacceptable in a context with a negated change-of-state, i.e. they do entail prior change (7b). This suggests the correctness of the BTR-compatible traditional analysis of change-of-state verbs for PC roots as in (1).

However, the prediction in (7c) is not borne out - adjectival forms of result roots like those in (7b) entail a change of the kind described by the verb they are derivationally related to (Koontz-Garboden 2005, 2010, Deo et al. 2011).

(10) a. \#The shattered vase has never (been) shattered.

b. \#The smashed windows have never been smashed.

c. \#The dead man never died.

d. \#The cooked chicken has never been cooked.

One possible counterexample are so-called "derived statives" (Nedjalkov \& Jaxontov 1988), where a deverbal adjective occurs in a context where there was no prior event of change:

(11) ...this paper provides a guide for writing letters that extend below the baseline. Internal broken lines serve as a reference for writing half-space letters.

(http: / / www . abledata.com/abledata. cfm?pageid=19327\&top=11104\& ksectionid=0 \&productid=79080\&trail=22,10\%825,11088\&discontinued=0) 
However, this is not evidence of a (5a)-type structure for these adjectives since the same apparently non-change-of-state usage occurs with verbal forms as well (e.g. The line breaks several times across the page). This suggests that uses like (11) are deverbal, realizing a structure similar to (5b). Second, while there is no change-of-state in (11) from a prior state across time, an increasing body of literature has shown that change-of-state need not be a purely temporal notion, but that changes can also be measured along a spatial scale (Gawron 2006) or even non-spatial scales like changes across populations (Deo et al. 2011, 2013). The use of broken in (11) describes change across space - as one moves right to left along the page there is a line, then a gap, and then a line, over and over again. That broken entails change even if not temporal is evidenced by (12), where a double line containing a gap labeled "W" can be described as broken at that point, but not one where the "W" labels a point prior to the beginning of the double line.

a.

The double line is broken at $\mathrm{W}$.

b. $W$

\#The double line is broken at $\mathrm{W}$.

Thus change is still part of the meaning of the adjective here, albeit in this case change is measured across space rather than across time (see Gawron 2006, Koontz-Garboden 2010, Deo et al. 2013 for arguments that the two notions of change are essentially the same except for the dimension of change).

Thus result roots seem to entail change in their adjectival forms while at least one adjectival form of PC roots does not. Now, this distinction could be a fluke of these English roots, e.g. perhaps result roots for some reason always require a $v_{\text {become }}$ head for categorization so that adjectives based on them will be necessarily deverbal (i.e. (5a) is banned, leaving just (5b)). However, we also see a split across the two type of roots under again modification that complicates this analysis. PC root verbs allow both restitutive and repetitive interpretations with again, so that (13) is ambiguous between a reading where the rug was created flat, got made not flat, and John restored its prior state, and a reading where it has undergone two flattening events. This supposedly follows from a scopal ambiguity where again either scopes over just the state-denoting root in (1a) or some larger verbal structure, as in (13a) and (13b) respectively.

(13) John flattened the rug again.

a. $\left[v \mathrm{P}\right.$ John $\left[v^{\prime} v_{\text {cause }}\left[v \mathrm{P}\right.\right.$ the $\operatorname{rug}\left[-e n_{v_{\text {become }}}[\sqrt{f l a t}\right.$ again $\left.\left.\left.\left.]\right]\right]\right]\right]$

(restitutive)

b. $\left[\left[v \mathrm{P}\right.\right.$ John $\left[v^{\prime} v_{\text {cause }}\left[v \mathrm{P}\right.\right.$ the rug $\left.\left.\left.\left[-e n_{v_{\text {become }}} \sqrt{\text { flat }}\right]\right]\right]\right]$ again $]$

(repetitive)

This is as expected under the BTR: on the restitutive reading again scopes over only a root, and roots do not entail change, so no prior change is inferred. However, as Rappaport Hovav (2010: 7) and Beavers \& Koontz-Garboden (2012: 358) observe, result roots do not allow pure restitutive readings. Rather, they only have a repetitive reading. For example, under again modification, thaw, melt, drown, and guillotine all necessarily entail two full change events, disallowing any sort of restitutive reading (e.g. a restored non-frozeness, liquidness, or death or injury as appropriate):

(14) a. John thawed the meat again. (necessarily two thawings)

b. John melted the soup again. (necessarily two meltings)

c. John drowned the zombie again. (necessarily two drownings) 
d. John guillotined the zombie again.

(necessarily two guillotinings)

This lack of semantic uniformity is quite difficult to analyze on a decompositional approach, since on a standard analysis of change-of-state verbs restitutive attachment should always be possible and by the BTR this would exclude change from the scope of again. One possible workaround would be to say that the event structures of result root change-of-state verbs somehow disallow this attachment, though it is difficult to see how this would come about. However, if this pattern was truly an idiosyncratic feature of English, then perhaps the clean divide between contributions by roots and templates posited by the BTR would still hold modulo some unusual stipulations about possible attachment sites. We show next that the asymmetries between result and PC roots are robustly found across languages. We look first at morphology and then semantics.

5. Morphology. Data published in prior literature already suggests that the morphological patterns found in English also occur in other languages as well (on Eastern Armenian see Megerdoomian 2002: 98, on Ulwa see Koontz-Garboden 2006, 2009b, on Tongan see Koontz-Garboden 2005, on O'odham, Hale \& Keyser 1998: 92, on Pima see Smith 2006: 3), though there are some gaps in the data. To explore this question more thoroughly we examined a balanced language sample to check for the existence of simple statives based on PC and result roots. For PC roots we searched for roots corresponding to Dixon's eight major PC root types, choosing the terms he listed as most frequently being lexicalized as adjectives across languages. For result roots, we chose roots underlying change-of-state verb classes from Levin (1993) that seemed most discussed in the literature as somehow canonical change-of-state verbs that seemed intuitively general enough to recur across languages. The roots we are interested in are those that correspond to the English adjective and verb paradigms in (15) and (16), illustrated in each case using the root's most unmarked form (adjective or verb, depending on the root, with synonyms or hypernyms given in parentheses that we also considered), for a total of 84 root meanings.

\section{(15) Property concept roots}

a. Dimension: large (big), small, short, long, deep, wide, tall (height)

b. Age: old (age)

c. Value: bad (worse), good

d. Color: white, black, red, green, blue, brown

e. Physical Property: cool, cold, warm, hot, dirty, dry, wet, straight, hard, tough, soft, tight, clear, clean, smooth, sharp, sweet, weak, strong

f. Speed: fast, slow

g. Human Propensity: angry, calm, scare (frighten), sick, sad (depress), hurt, tire, embarrass, entertain, surprise, worry, please

\section{(16) Result roots}

a. Entity-specific Change of State: burn, melt, freeze, decay (rot), swell, grow, bloom (flower, blossom), wither (wilt), ferment, sprout (germinate), rust, tarnish

b. Cooking Verbs: cook (bake, fry, roast, steam), boil

c. Breaking Verbs: break, crack, crush, shatter, split, tear (rip), snap

d. Bending Verbs: bend, fold, wrinkle (crease) 
e. Verbs of Killing: dead/die/kill, murder, drown

f. Destroying Verbs: destroy (ruin)

g. Verbs of Calibratable Change of State: go up (rise, ascend, increase, gain), go down (fall, drop, descend, decrease, decline), differ

h. Verbs of Inherently Directed Motion: come, go, go in (enter), go out (exit), return

Our methodology consisted of a dictionary and grammar-mining study of equivalent roots in other languages, using these English terms (or equivalents in other metalanguages) as initial search terms. For this we targeted the World Atlas of Language Structures 100 Language Sample (Dryer \& Haspelmath 2013), although some modifications were required for our final language list. In some cases we lacked sufficient grammatical and dictionary resources and therefore substituted languages from the sister WALS 200 list covering similar geographic regions and language families. We also opportunistically added in a few other languages not on either list based on available resources or native speakers/fieldworkers. Finally, some languages had to be dropped and not replaced if we had no resources on comparable languages. The final total was 88 languages, mostly covering the original areas and families of the WALS 100, 73 of which we have completed data collection for and include in our analysis below (excluding those marked with $\left.{ }^{*}\right){ }^{1}$

(17) a. Africa: Acholi (Nilotic, Eastern Sudanic), *Egyptian Arabic (Semitic, Afro-Asiatic), Harar Oromo (Lowland East Cushitic, Afro-Asiatic), *Hausa (West Chadic, Afro-Asiatic), Gújjolaay Eegimaa (Bak, Niger-Congo), Khoekhoe (Khoe-Kwadi), ${ }^{*}$ Kinyarwanda (Bantoid, Niger-Congo), Koyraboro Senni (Songhay), Malagasy (Barito, Austronesian), Middle Atlas Berber (Berber, Afro-Asiatic), Sango (Ubangi, Niger-Congo), Swahili (Bantoid, Niger-Congo), Yoruba (Defoid, Niger-Congo), Zulu (Bantoid, Niger-Congo),

b. Australia: Gooniyandi (Bunuban), Kayardild (Tangkic, Tangkic), Martuthunira (Western Pama-Nyungan, Pama-Nyungan), ${ }^{*}$ Murrinh-Patha (Murrinh-Patha, Southern Daly), Pintupi (Western Pama-Nyungan, Pama-Nyungan), Tiwi (Tiwian)

c. Eurasia: Basque (Basque), *Burmese (Burmese-Lolo, Sino-Tibetan), ${ }^{*}$ Burushaski (Burushaski), *Chukchi (Northern Chukotko-Kamchatkan, Chukotko-Kamchatkan), English (Germanic, Indo-European), Finnish (Finnic, Uralic), French (Romance, Indo-European), Georgian (Kartvelian), German (Germanic, Indo-European), Hindi (Indic, Indo-European), Japanese (Japanese), *Kannada (Southern Dravidian, Dravidian), Khalkha (Mongolic, Altaic), Korean (Korean), Lezgian (Lezgic, Nakh-Daghestanian), Mandarin (Chinese, Sino-Tibetan), *Meithei (Kuki-Chin, Sino-Tibetan), Modern Greek (Greek, Indo-European), Modern Hebrew (Semitic, Afro-Asiatic), Persian (Iranian, Indo-European), Russian (Slavic, Indo-European), Spanish (Romance, Indo-European), Thai (Kam-Tai, Tai-Kadai), Turkish (Turkic, Altaic), Vietnamese (Viet-Muong, Austro-Asiatic)

d. North America: Chalcatongo Mixtec (Mixtecan, Oto-Manguean), Hopi (Hopi, Uto-Aztecan), Jakaltek (Mayan), Karok (Karok), Kiowa (Kiowa-Tanoan), Koasati (Muskogean), *Kutenai (Kutenai), Lakhota (Core Siouan, Siouan), ${ }^{*}$ Mezquital Otomí

\footnotetext{
${ }^{1}$ All macroareas and genetic affiliations are taken from WALS. Each language is listed with its genus and family, except where those are the same.
} 
(Otomian, Oto-Manguean), Navajo (Athapaskan, Na-Dene), Oneida (Northern Iroquoian, Iroquoian), Plains Cree (Algonquian, Algic), Rama (Rama, Chibchan), Tenango Tzeltal (Mayan), Yaqui (Cahita, Uto-Aztecan), Yup'ik (Eskimo, Eskimo-Aleut), Zoque (Mixe-Zoque)

e. Papunesia: Alamblak (Sepik Hill, Sepik), Anejom (Oceanic, Austronesian), Bariai (Oceanic, Austronesian), Chamorro (Chamorro, Austronesian), Daga (Dagan), Fijian (Oceanic, Austronesian), Hawaiian (Oceanic, Austronesian), Indonesian (Malayo-Sumbawan, Austronesian), Kewa (Engan, Trans-New Guinea), Koiari (Koiarian, Trans-New Guinea), Kwoma (Middle Sepik, Sepik), Lower Grand Valley Dani (Dani, Trans-New Guinea), *Oksapmin (Oksapmin), Paiwan (Paiwan, Austronesian), Tagalog (Greater Central Philippine, Austronesian)

f. South America: Barasano (Tucanoan), Carib (Cariban), Guaraní (Tupi-Guaraní, Tupian), Huallaga Quechua (Quechuan), Kakataibo (Cashibo-Cacataibo, Panoan), Mapudungun/Mapuche (Araucanian), Minica Huitoto (Huitoto, Huitotoan), *Mocoví (South Guaicuran, Guaicuran), Paumarí (Arauan), Warao (Warao), *Yagua (Peba-Yaguan)

In looking for equivalents to (15) and (16) across languages we did not assume all translations were perfect, just that the meanings were similar enough to the original root to constitute falling into the same narrow (and thus broad) root class. We checked translations in both directions to ensure that we had a reasonable sense of the full range of meaning of the given term as presented by the author of the relevant resource. We collected paradigms of simple state-inchoative-causative-result state (e.g. red-redden-redden-reddened) for each root in the target language, plus also any underlying root for languages in which such paradigms are based on a shared bound morpheme. Thus the paradigm for the meaning 'small' in Tenango Tzeltal had no underlying root, while the paradigm for 'long' in Oromo did:

\begin{tabular}{l|ccccc} 
Language & underlying root & simple state & inchoative & causative & result state \\
\hline Tenango Tzeltal & - & tut & tut-ub & tut-ub-tes & tut-ub-en \\
'small' & 'shrink' & 'shrink' & 'shrunken' \\
Oromo & $\begin{array}{c}\text { dheer-aa } \\
\text { dheer-addh }\end{array}$ & $\begin{array}{c}\text { dheer-essuu } \\
\text { 'long' }\end{array}$ & 'become long' & 'lengthen' &
\end{tabular}

For simple states we looked for predicative forms, including possessive predicational strategies (Francez \& Koontz-Garboden 2015). If a form was unattested but our resources gave productive processes for deriving it, we constructed a hypothetical form (marked by @ so it could be left out of the analysis if need be). This was needed for agglutinating languages such as Kiowa where some dictionaries give roots and rules rather than full forms (Watkins \& McKenzie 1984: 153):

\begin{tabular}{l|ccccc} 
Language & underlying root & simple state & inchoative & causative & result state \\
\hline Kiowa & - & $e ́ t$ & @ét- $\delta m-g y a ́$ & @ét- $\delta m$ & @ét- $d \delta$ - \\
& & 'big' & 'enlarge' & 'enlarge' & 'enlarged'
\end{tabular}

We privileged lexicalized terms over productively derived terms, and morphologically derived terms over periphrastically derived terms, motivated by a general tendency across languages for more lexical(ized) forms to be "normal" or "default" expressions, followed by synthetic forms, and then analytical forms (see e.g. the literature on causatives; Shibatani \& Pardeshi 2001). The ultimate preference rankings for the forms we collected were: 
(20) attested lexicalized form $>$ attested morphological form $>$ hypothetical morphological form $>$ attested periphrastic form $>$ hypothetical periphrastic form $>$ no data

If we found synonyms we collected data on all synonymous terms. To determine the semantic category of a term (i.e. simple state, inchoative, causative, result state term) we had two options: use translation (qua semantics) as a guide or use morphology as a guide. For consistency, we used the dictionary translation to determine the basic category of a term regardless of the morphology, e.g. if a morphologically simple stative term was translated as result state adjective broken we listed it as a result state term. However, we also recorded morphological information about each language and in particular coded each item in each paradigm for its morphological relationship to all other items in the same paradigm in terms of an expansion of the classification of causative/inchoative pair terms from Haspelmath (1993), where a pair of terms within a paradigm might be related by direct derivation (one is input to the other) or indirect derivation (one is input to a term that is input to the other), labile (identical), equipollent (both derived from the same input), or suppletive (unrelated by any clear derivation process). From this it is possible to reconstruct a purely morphological classification of terms and compare it to the semantic classification (though the two rarely disagreed). Finally, for some languages we used fieldworkers to collect the data or got it directly from native speakers, though the methodology was equivalent.

From a simple visual inspection of the data collected so far the main overall pattern holds: PC roots overwhelmingly tend to have simple stative forms (that also tend to be relatively unmarked compared to the rest of the members of the paradigm save the underlying root if one exists), while result roots overwhelmingly tend not to have corresponding simple stative terms (though there are exceptions in both directions). In other words, the following difference between a PC and result root in Tenango Tzeltal is typical:

\begin{tabular}{l|ccccc} 
Language & underlying root & simple state & inchoative & causative & result state \\
\hline Tenango Tzeltal & - & $t u t$ & $t u t-u b$ & tut-ub-tes & tut-ub-en \\
& & 'small' & 'shrink' & 'shrink' & 'shrunken' \\
Tenango Tzeltal & - & - & $c h i j k$ & chik' & chijk'-em \\
& & & burn & burn & burned
\end{tabular}

A statistical analysis confirms this pattern, albeit with some specific assumptions about what to do with parts of paradigms for which we had no data for purposes of such an analysis. In particular, we ignored altogether any root meanings for which we had no data for any member of the paradigm in a given language, on the assumption that in this case there is a way to convey the concept but we lacked resources that told us what it was (e.g. we were unable to find any data for a root meaning 'hurt' in Anejom, so we assumed we had a gap in the dictionary). Otherwise, we took a missing member of a paradigm to be evidence of the lack of that form in the language. If a root meaning corresponded to several apparent synonyms, for purposes of our statistical analysis we took one random synonym. We ended up with $3120 \mathrm{PC}$ and 2241 result roots, for a total of 5361 paradigms. Each paradigm had 5 cells for a total of 26,805 possible forms; $>17,000$ figured into our analysis (this last number may change depending on which of multiple synonyms was randomly chosen). We compared the median percentages of attested simple states for PC and result roots (and deviation from the median) across languages, and the differences shown in Figure 1 were statistically significant (on a Mann Whitney U-test on the median proportion of simple statives for PC and result roots at $86.62 \%$ and $1.82 \%$ respectively; $U=1702, p<0.001$ ) (and the significance did not change if we threw out hypotheticals; $U=1702.5, p<0.001$ ). 


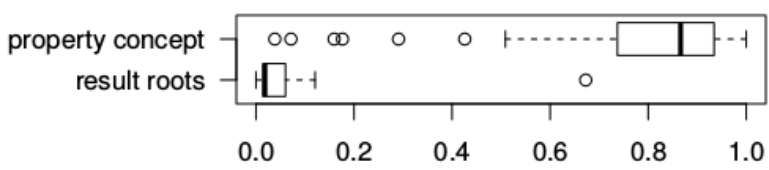

Figure 1. Proportion of filled simple states by major root class

The differences are fairly consistent across subclasses, where subclasses of PC roots tend to cluster together in largely having simple stative forms and subclasses of result roots tend to cluster together in overwhelmingly lacking simple stative forms, as illustrated visually in Figure 2.

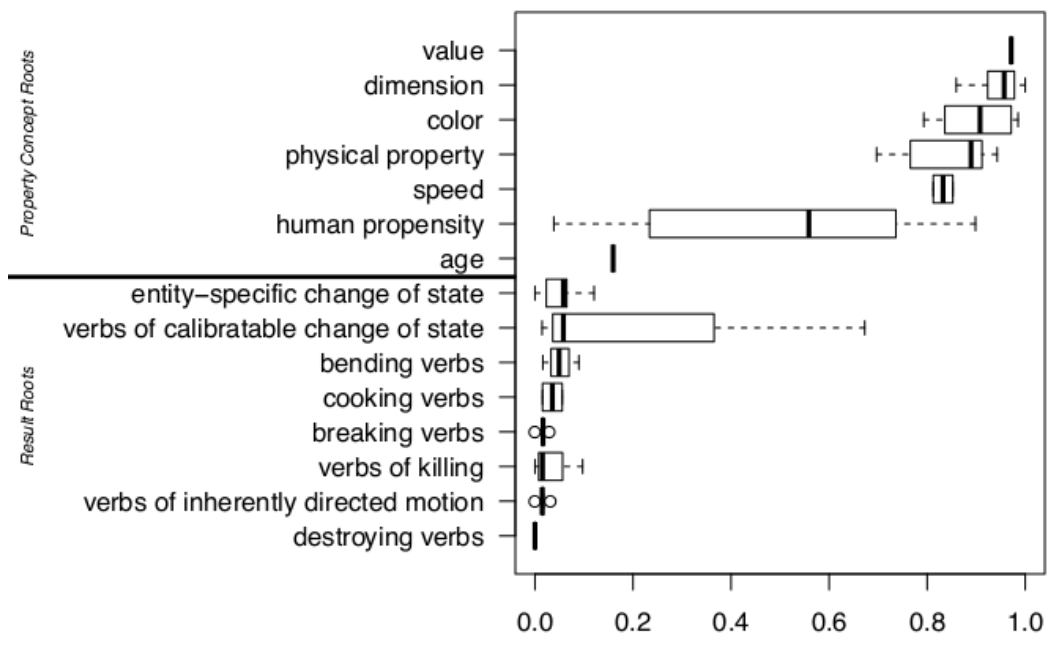

Figure 2. Proportion of filled simple states by root subclass

There are two notable exceptions to these trends. First, age roots pattern like result roots rather than PC roots pretty resoundingly, though this followed from an analytic decision on our part: the only root concept we took from this class was one meaning 'old' (or 'aged'), and definitionally 'old' is semantically based on a result root since something or someone cannot be old without having first not been old. (In fact, the OED claims English old itself is historically deverbal, from the past participle of Old English alan "nourish", though this verb is in turn apparently deadjectival; Elly van Gelderen, p.c.) The other stand out is human propensity, which included a number of psych verbs. Here, however, there was potentially a semantic category problem: many psych verbs allow both stative and eventive verbal meanings, the former lacking a change (e.g. if someone is born with a congenital defect that causes constant pain The congenital defect hurts her is true but there is no change), and thus deverbal adjectives from these may or may not entail change. Similarly, transitive experience-subject psych verbs are not easily analogizable to caused change-of-state verbs. Thus it is difficult to be certain whether the relevant terms in other languages are eventive or stative, and thus how best to classify them. Despite these two complications, the trend seems clear. The crosslinguistic morphological generalization is that state-denoting words based on result roots do not exist in the morphological form that PC roots do. The former tend to lack simple stative forms, the latter have them.

6. Semantics. To test the semantic predictions cross-linguistically we chose opportunistic in-depth studies, using Kinyarwanda (Northeastern Bantu; Rwanda) and Kakataibo (Panoan; 
Eastern Peru) as case studies (see Jerro 2017 and Valle et al. 2017, respectively). For space reasons we present only the data from Kakataibo, for which we examined the following roots: ${ }^{2}$

(22) Property concept roots: xo paxada 'yellow', ani 'big, upi(t) 'pretty, beautiful', tuna(n) 'black', uxu(a) 'white', inru 'hard', xana 'hot', bata 'sweet', bachu 'soft', 'aidama 'bad', bënsi(t) 'thin', xëni 'old', chadkë $(t)$ 'thin', chabat 'wet', puntë( $(t)$ 'straight', diba(t) 'smooth', kacha 'sour', anaha 'wide', chukúma 'small', cha 'big', mamúa 'round'

(23) Result roots: $\ddot{e} d-k i$ - $k \ddot{e}$ 'dry-INTR-NMLZ', tëa-kë 'cut-NMLZ', nën 'burn', nën-kë

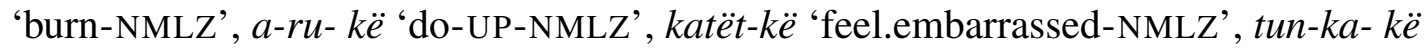
'shoot-TR-NMLZ', rëtë 'kill', kë̄n 'exterminate', chachi 'stab', xui 'barbecue', sasa-ka 'fry-TR', musa 'mix/stir/mash'

Typically in Kakataibo simple state terms are adjectives that are superficially labile with the inchoative despite the category difference, while result state terms are derived by factive morpheme $-k \ddot{e}$. Consistent with the discussion above, PC roots usually have simple stative terms but result roots usually lack them, but both have result state terms, e.g. the following is typical:

\begin{tabular}{l|ccccc} 
Language & underlying root & simple state & inchoative & causative & result state \\
\hline Kakataibo & - & $a n i$ & $a n i$ & ani-o & ani(-o)-kë \\
& & 'large' & 'enlarge' & 'enlarge' & 'enlarged' \\
& - & - & churi & churi-o & churi(-o)-kë \\
& & & 'wrinkle' & 'wrinkle' & 'wrinkled'
\end{tabular}

Crucially, PC vs. result roots show the expected distinction regarding change entailments. A change-of-state can be denied when using a simple state, but there is no corresponding simple state for the result root and the stative forms that do exist require change-of-state.
a. báinka
ani 'ikë
'aibika
uini
abi ni
báin $=\mathrm{ka}=\mathrm{a}$
ani 'ikë
'ai=bi=ka=a
uini $\quad a=b i \quad$ ni
hill $=\mathrm{VAL}=3 \mathrm{~A} / \mathrm{s}$ big be. $3 . \mathrm{IPFV}$ then=EMPH=VAL=3 A/S INDF.PRO $3=\mathrm{EMPH}$ nor
Diosabi ni uni yubë unibi anioima.
Diosabi ni uni yubët uni=bi ani-o-i-i=ma.
God=EMPH nor man sorcerer man=EMPH big-FACT- $\mathrm{IPFV}=\mathrm{PROX}=\mathrm{NEG}$
'The hill is big, but nobody nor God nor a sorcerer made it big.'

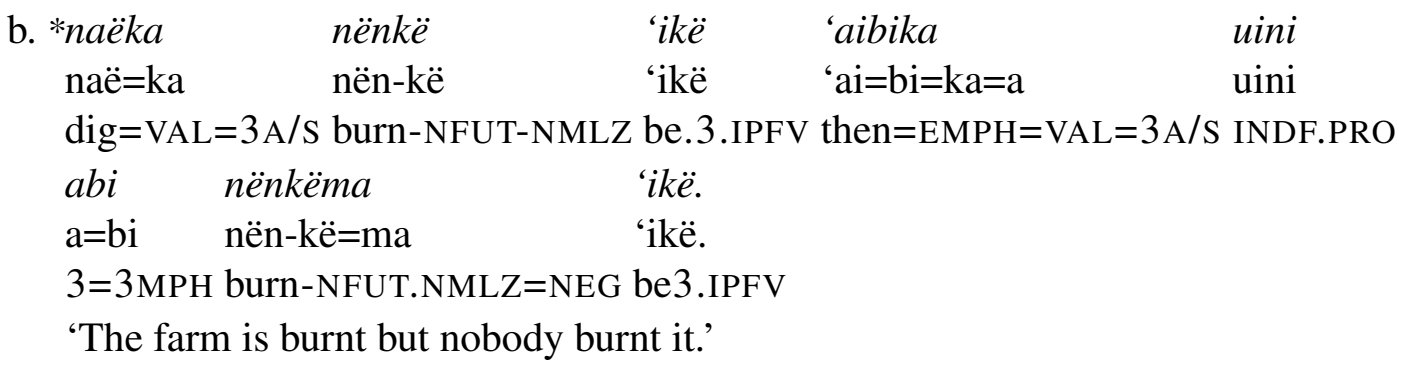

Similarly, the two root classes differ in whether restitutive modification is allowed or not. It is easy to get this for PC roots, but the default reading for result roots is that two events of the type

\footnotetext{
${ }^{2} 3=$ third person, $A=$ subject of transitive verb, EMPH=emphatic, FACT=factitive, INDF=indefinite, INTR=intransitive, IPFV=imperfective, ITR=iterative, NEG=negation, NFUT.NMLZ=non-future nominalizer, POSS=possessive, $\mathrm{PRO}=$ pronoun, $\mathrm{PROX}=$ proximate, $\mathrm{S}=$ subject of intransitive verb, UP=up, $\mathrm{VAL}=$ validational
} 
described happened. This was true even if a context was supplied that clarified a possible restitutive reading, though it is sometimes very difficult to determine what that state could possibly be. For example, it is difficult to get at what the outcome of a frying event might be independent of the frying itself, though that the food is somehow "hot and edible" is a reasonable attempt at that. However, in a context where a banana is found hot and edible and is made cold and inedible by magic and then someone fries it into its original state again, (26b) is still bad.

(26) a. [ The desert starts off dry. Then, it is made non-dry. Then it turns dry again. ]

$$
\begin{array}{lll}
\text { madin } & \text { papanka } & \text { ëdkitëkënia } . \\
\text { madi }=\mathrm{n} & \text { papa }=\mathrm{n}=\mathrm{ka}=\mathrm{a} & \text { ëd-ki-tëkën-i-a. } \\
\text { sand }=\text { POSS father }=\mathrm{A} / \mathrm{S}=\mathrm{VAL}=3 \mathrm{~A} / \mathrm{s} \text { dry-INTR-ITR-IPFV=N.PROX }
\end{array}
$$

'The desert is getting dry again.'

b. [ The man picks up a hot banana, which is edible. A wizard makes it inedible and cold. The man fries the banana and makes it hot and edible again. ]

$$
\begin{array}{lll}
\text { \#uninka } & \text { nodi } & \text { sasakatëkënia. } \\
\text { uni=n=ka=a } & \text { nodi } & \text { sasa-ka-tëkën-a-X-a } \\
\text { man=A/S=VAL=3 A/s banana fry-TR-ITR-PFV-3-N.PROX }
\end{array}
$$

'The man fried the banana again.'

Rather, the reading of (26b) is that there were two frying events. Thus, while PC roots behave as predicted by the BTR having a purely stative meaning, result roots always have an entailment of change, a fact that holds up across languages.

7. Conclusions and consequences. Both $\mathrm{PC}$ and result roots differ consistently across languages in terms of the inferences they generate and their morphological behavior. Result roots but not PC roots seem to categorically entail change-of-state even in templates lacking $v_{\text {become, }}$, and PC roots but not result roots tend to have simple stative forms. These predictions violate the BTR, which stipulates that no stative root should entail change, and that the morphological structures of statives built from such roots should be identical barring lexical idiosyncrasy.

A simple analysis would be to abandon the BTR and assume that PC roots describe simple states without change while result roots additionally entail some prior change-of-state event:
a. $\llbracket \sqrt{\text { flat }} \rrbracket=\lambda x \lambda s\left[\operatorname{flat}^{\prime}(x, s)\right]$
b. $\llbracket \sqrt{\operatorname{crack}} \rrbracket=\lambda x \lambda s\left[\right.$ has.fissure $\left.(x, s) \wedge \exists e^{\prime}\left[\operatorname{become}^{\prime}\left(e^{\prime}, s\right)\right]\right]$

This might be what Rappaport Hovav \& Levin (1998) have in mind in saying that break type verbs are built on 'result states'. (See similar conclusions for certain change-of-state verbs based on modifier data in Piñón 1999 and Kratzer 2000.) Defining $v_{\text {become }}$ as in (28a) and combining it with (27) derives the inchoatives in $(28 b, c)$.

$$
\begin{array}{ll}
\text { a. } & \llbracket v_{\text {become }} \rrbracket=\lambda P \lambda x \lambda e \exists s[\text { become } \\
\text { b. } & \llbracket v_{\text {become }} \sqrt{\text { flat }} \rrbracket=\lambda x \lambda e \exists s[\text { become } \\
\text { c. } & \llbracket v_{\text {become }} \sqrt{\operatorname{crack}} \rrbracket=\lambda x \lambda e \exists s\left[\text { become }(e, s) \wedge \operatorname{flat}^{\prime}(x, s)\right] \\
\text { has.fissure } & \left.(x, s) \wedge \exists e^{\prime}\left[\operatorname{become}^{\prime}\left(e^{\prime}, s\right)\right]\right]
\end{array}
$$

The change-of-state use of the PC root only entails change by virtue of $v_{\text {become }}$, but the crack root has the entailment itself. This predicts that other uses of the root without $v_{\text {become }}$ will give rise to the entailment. If $\operatorname{Asp}_{(R)}$ is defined semantically in (29a) then the two stative roots in (27) will 
differ in that only the stativized version of the former will lack an entailment of change while the former will have it owing to the root semantics:
a. $\llbracket \operatorname{Asp}_{(R)} \rrbracket=\lambda P \lambda x \lambda s[P(x, s)]$
b. $\llbracket \operatorname{Asp}_{(R)} \sqrt{\text { flat }} \rrbracket=\lambda x \lambda s\left[\wedge \operatorname{flat}^{\prime}(x, s)\right]$
c. $\llbracket \operatorname{Asp}_{(R)} \sqrt{\operatorname{crack}} \rrbracket=\lambda x \lambda s\left[\right.$ has.fissure $\left.(x, s) \wedge \exists e^{\prime}\left[\operatorname{become}^{\prime}\left(e^{\prime}, s\right)\right]\right]$

Finally, if again scopes over just (27b) then an event of change is entailed to have occurred before, deriving a repetitive reading. Thus this analysis captures the semantic facts above. For the morphology, a simple analysis would be to adopt the following default realization rules for Asp and $v$ heads at Spell-Out (overridden by root-specific rules as with old):

(30) Default realization of $v_{\text {become }}$ with complement $\operatorname{root} \sqrt{\mathrm{R}}$ :

a. If $\sqrt{\mathrm{R}}$ entails change, then $-\emptyset$

(result roots make unmarked verbs)

b. If $\sqrt{\mathrm{R}}$ does not entail change, then -en/ed

(PC roots make marked verbs)

(31) Default realization for $\operatorname{Asp}_{(R)}$ with complement XP (root $\sqrt{\mathrm{R}}$ or $\left.v \mathrm{P}\right)$ :

a. If XP does not entail change, then $-\emptyset$

( $\mathrm{PC}$ roots make unmarked adjectives)

b. If XP entails change, then -en/ed

(result roots make marked adjectives)

This has a simple functional motivation: the two categories are unmarked for opposite meanings. However, these rules go against the grain of standard event structural approaches, whereby regular morphological rules should not be sensitive to root semantics. Yet it seems clear that the pattern governing the overt realization must be contingent on root semantics, suggesting the overall correctness of our analysis, arguing against that aspect of event structural theories. ${ }^{3}$

Finally, the question arises of why there should be two types of stative roots in the first place. Here we believe the reason is largely conceptual. There are certain kinds of states that people can conceive of as existing independent of any process that leads to them, while there are other types of states that only arise if there is a process that leads to them. In the latter case, then, for a root to entail the state means it will entail a change as well. Since change is itself already a semantic category that has grammatical consequences - being the basis of $v_{\text {become }}$ - then if processes in a language are sensitive to this type of meaning they will treat such roots differently from roots lacking this entailment. In sum, the root carries an entailment that can be elsewhere introduced templatically, and it can matter grammatically, something inconsistent with the BTR.

\section{References}

Arad, Maya. 2005. Roots and patterns: Hebrew morpho-syntax. Dordrecht: Springer. Beavers, John \& Andrew Koontz-Garboden. 2012. Manner and result in the roots of verbal meaning. Linguistic Inquiry 43(3). 331-369.

\footnotetext{
${ }^{3}$ A way around this would be to adopt an approach like Ramchand (2008) and others, where roots have morphosyntactic features that describe what sorts of functional heads they must compose with, e.g. $\sqrt{\text { crack }}$ could have a [+become] feature that requires it to compose with a $v_{\text {become }}$ head. This ensures the morphological fact that an adjective based on it will always be deverbal while also avoiding have to have Spell-Out rules be sensitive to semantics. However, this approach has two problems. First, the semantic analysis we have outlined is still needed in order to capture the again modification facts, and thus, second, the featural analysis is essentially redundant and works as a stipulation to get around having morphological rules be sensitive to truth-conditional semantics.
} 
Beavers, John \& Andrew Koontz-Garboden. 2017. The semantic contribution of idiosyncratic roots to ditransitive verbs. In Proceedings of the 34th West Coast Conference on Formal Linguistics, Summerville: Cascadilla Proceedings Project.

Beavers, John \& Andrew Koontz-Garboden. In prep. The meaning of verbal roots and the roots of verbal meaning. Unpublished Ms., The University of Texas at Austin and The University of Manchester.

Borer, Hagit. 2005. Structuring sense, vol. I and II. Oxford: Oxford University Press.

Deo, Ashwini, Itamar Francez \& Andrew Koontz-Garboden. 2011. The morphosemantics of -ed. Paper presented at Dimensions of grammar in honor of Paul Kiparsky. Konstanz, August 3, 2011.

Deo, Ashwini, Itamar Francez \& Andrew Koontz-Garboden. 2013. From change to value difference in degree achievements. In Proceedings of Semantics and Linguistic theory 23, 97-115. Ithaca, NY: CLC Publications.

Dixon, R.M.W. 1982. Where have all the adjectives gone? The Hague: Mouton.

Dowty, David. 1979. Word meaning and Montague grammar. Dordrecht: D. Reidel Publishing.

Dryer, Matthew S. \& Martin Haspelmath (eds.). 2013. Wals online. Leipzig: Max Planck Institute for Evolutionary Anthropology. http://wals.info/.

Dunbar, Ewan \& Alexis Wellwood. 2016. Addressing the "two interface" problem: Comparatives and superlatives. Glossa 1(1). 1-29.

Embick, David. 2004. On the structure of resultative participles in English. Linguistic Inquiry 35(3). 355-392.

Embick, David. 2009. Roots, states, and stative passives. Talk given that the 2009 Roots Workshop, Stuttgart.

Francez, Itamar \& Andrew Koontz-Garboden. 2015. Semantic variation and the grammar of property concepts. Language 91. 533-563.

Gawron, Jean Mark. 2006. Paths and scalar change. Unpublished Ms., San Diego State University, dated May 18, 2006.

Goldberg, Adele E. 1995. Constructions: A construction grammar approach to argument structure. Chicago, IL: University of Chicago Press.

Hale, Kenneth L. \& Samuel Jay Keyser. 1998. The basic elements of argument structure. In Papers from the UPenn/MIT roundtable on argument structure and aspect, vol. 32, 73-118. MITWPL.

Hale, Kenneth L. \& Samuel Jay Keyser. 2002. Prolegomenon to a theory of argument structure. Cambridge, MA: MIT Press.

Harley, Heidi. 2012. Lexical decomposition in modern syntactic theory. In Wolfram Hinzen, Edouard Machery \& Markus Werning (eds.), The Oxford handbook of compositionality, 328-350. Oxford: Oxford University Press.

Haspelmath, Martin. 1993. More on the typology of inchoative/causative verb alternations. In Bernard Comrie \& Maria Polinsky (eds.), Causatives and transitivity, 87-120. Amsterdam: John Benjamins.

Jerro, Kyle. 2017. Change-of-state verb roots in Kinyarwanda. Paper presented at the Linguistic Society of America 91st Annual Meeting, Austin, TX.

Koontz-Garboden, Andrew. 2005. On the typology of state/change of state alternations. Yearbook of Morphology 2005. 83-117.

Koontz-Garboden, Andrew. 2006. The states in changes of state. In Proceedings of the 32nd 
annual meeting of the Berkeley Linguistics Society.

Koontz-Garboden, Andrew. 2007. Aspectual coercion and the typology of change of state predicates. Journal of Linguistics 43(1). 115-152.

Koontz-Garboden, Andrew. 2009a. Anticausativization. Natural Language and Linguistic Theory 27. 77-138.

Koontz-Garboden, Andrew. 2009b. Ulwa verb class morphology. International Journal of American Linguistics 75(4). 453-512.

Koontz-Garboden, Andrew. 2010. The lexical semantics of derived statives. Linguistics and Philosophy 33. 285-324.

Koontz-Garboden, Andrew \& John Beavers. 2017. Change of state verbs and the semantics of roots. In Proceedings of the 34th West Coast Conference on Formal Linguistics, Summerville: Cascadilla Proceedings Project.

Kratzer, Angelika. 2000. Building statives. In Proceedings of the 26th meeting of the Berkeley Linguistics Society, 385-399. Berkeley, CA: Berkeley Linguistics Society.

Levin, Beth. 1993. English verb classes and alternations. Chicago, IL: University of Chicago Press.

Marantz, Alec. 1997. No escape from syntax: Don't try morphological analysis in the privacy of your own lexicon. In Proceedings of the 21 st annual Penn Linguistics Colloquium, vol. 4.2 University of Pennsylvania Working Papers in Linguistics, 201-225.

Megerdoomian, Karine. 2002. Beyond words and phrases: A unified theory of predicate composition. Los Angeles, CA: University of Southern California dissertation.

Nedjalkov, Vladimir P. \& Sergej Je. Jaxontov. 1988. The typology of resultative constructions. In Vladimir P. Nedjalkov (ed.), Typology of resultative constructions, 3-62. Amsterdam: John Benjamins.

Piñón, Christopher. 1999. Durative adverbials for result states. In Proceedings of the West Coast Conference on Formal Linguistics, 420-433. Somerville, MA: Cascadilla Press.

Ramchand, Gillian. 2008. Verb meaning and the lexicon: A first phase syntax. Cambridge: Cambridge University Press.

Rappaport Hovav, Malka. 2010. Building scalar changes. The Hebrew University of Jerusalem.

Rappaport Hovav, Malka \& Beth Levin. 1998. Building verb meanings. In Miriam Butt \& Willhel Geuder (eds.), The projection of arguments: Lexical and compositional factors, 97-133. Stanford: CSLI Publications.

Shibatani, Masayoshi \& Prashant Pardeshi. 2001. The causative continuum. In Masayoshi Shibatani (ed.), The grammar of causation and interpersonal manipulation, 85-126. Amsterdam: John Benjamins.

Smith, Marcus. 2006. Canalization of causative derivations. Paper presented at 2006 meeting of LSA, Albuquerque, New Mexico.

Valle, Daniel, John Beavers \& Andrew Koontz-Garboden. 2017. States and change-of-state in Kakataibo: The role of the root. Paper presented at the Society for the Study of the Indigenous Languages of the Americas.

Watkins, Laurel J. \& Parker McKenzie. 1984. A grammar of Kiowa. Studies in the Anthropology of North American Indians. Lincoln / London: University of Nebraska Press.

Wechsler, Stephen. 2005. What is right and wrong about little-v. In Mila Vulchanova \& Tor A. Åfarli (eds.), Grammar and beyond - essays in honour of Lars Hellan, 179-195. Oslo: Novus Press. 